\title{
Intelligent prediction of coal mine water inrush based on optimized SAPSO-ELM model under the influence of multiple factors
}

\author{
Yong-gang Zhang ${ }^{1} \cdot$ Yuan-lun Xie ${ }^{2} \cdot$ Li-ning Yang $^{3} \cdot$ Rao-ping Liao $^{1} \cdot$ Tao Qiu $^{4}$
}

Received: 12 November 2021 / Accepted: 16 February 2022 / Published online: 26 February 2022

(c) The Author(s) 2022

\begin{abstract}
Mine water inrush is affected by many factors such as geological structure and fracture zone. However, there may be overlap among these factors, leading to uncertainty, fuzzy similarity and nonlinear relationship among most of them. Therefore, the traditional mathematical model is not ideal to predict water inrush. This paper proposes an intelligent model for predicting water inrush from coal floor based on simulated annealing particle swarm optimization-extreme learning machine (SAPSOELM). Based on 144 groups of learning data and 36 groups of predictive validation data, the proposed model extracted common factors from 14 geological factors that might be related to water inrush in a mining area, so as to reduce information interaction among discriminant indexes. In this paper, simulated annealing particle swarm optimization (SAPSO) is innovatively used to optimize the model parameters and compared with other intelligent models (SVM, BPNN, PSO-ELM and ELM) for the learning prediction of the same data. The results show that the common factors extracted from the original variables contain most of the comprehensive information and can reduce information redundancy. Compared with traditional intelligent models (SVM, BPNN, PSO-ELM and ELM), the proposed model improves the computational efficiency of convergence, and the prediction accuracy is higher. It is proved that SAPSO-ELM intelligent algorithm is indeed scientific and has broad application prospect in result prediction induced by complex multi-factors.
\end{abstract}

Keywords Water inrush prediction $\cdot$ Factor analysis $\cdot$ Simulated annealing particle swarm optimization (SAPSO) $\cdot$ Extreme learning machine (ELM)

Responsible Editor: Santanu Banerjee

Li-ning Yang

lining.yang@ postgrad.manchester.ac.uk

$\triangle$ Rao-ping Liao

lrp_liao@tongji.edu.cn

1 Key Laboratory of Geotechnical and Underground Engineering of Ministry of Education, and Department of Geotechnical Engineering, Tongji University, Shanghai 200092, China

2 School of Information and Software Engineering, University of Electronic Science and Technology of China, Chengdu 610051, China

3 Department of Earth and Environmental Sciences, University of Manchester, Manchester M13 9PL, UK

4 School of Transportation, Southeast University, Nanjing 210000, China

\section{Introduction}

Coal is the main primary energy in China, accounting for more than $70 \%$ of the total energy consumption (Qiu et al. 2019; He et al. 2020a; Liu et al. 2020), which contributes to the rapid development of the social economy. However, coal mining causes many safety problems. Due to the influence of geological conditions and man-made operations, coal mines are prone to floods, fires and gas explosions during the mining process. Herein, floods caused the most direct economic losses and the second causalities with the second occurrence. In coal mine floods, accidents caused by the water inrush are particularly typical (Rui et al. 2018; Zhang et al. 2016, 2020c). In recent years, with the development of the coal mine disaster prediction technology, the occurrence of coal mine disasters and casualties is gradually decreasing. However, the situation is still bad that from January 2015 to December 2019, there were 223 coal mine disaster accidents, which lead to 1656 people deaths, including 52 water inrush accidents and 321 deaths (Qiu et al. 2020). Because 
of the differences in conditions of sedimentary deposition of coal seam, only some countries and regions are subject to the water inrush problems (Bai and Miao 2009; Miao et al. 2010; Yu et al. 2016; Liu et al. 2019; He et al. 2020b). Therefore, studies on water inrush problems have certain regional restrictions. In addition, the influence on water inrush problems is interacted by artificial inducements and disturbances from natural conditions, leading to the complexity in studying water inrush problems in coal mines.

A number of studies on water inrush prediction have been conducted previously, using data mining, neural network, support vector machine (SVM), extreme learning machine (ELM) and other technologies (Zhang et al. 2022a, b). Du et al. (2014) improved the decision tree model of the CART algorithm for data mining and used it to establish the water inrush prediction model, which solved the limitations of high computational workload and low accuracy of the original algorithm. Yan et al. (2008) designed a new method of top-down classification and construction of H-SVMs based on the maximum interval of SVM to predict the water inrush in coal mine. Wu and Zhou (2008) built a water inrush prediction model based on the vulnerability index method. Liu et al. (2009) applied a binary logistic regression model to analyze the influence of the main controlling factors on the water inrush from the coal seam floor. Li (2010) developed a coal mine floor water inrush prediction model using geographic information system (GIS). Liu et al. (2011) and Jin et al. (2011) proposed a real-time monitoring system for the water inrush problem in a coal mine and established a prediction model based on data mining classification technology. Wang et al. (2012) developed a water inrush prediction method based on rock mass limit equilibrium theory. Zhao et al. (2013) combined principal component analysis (PCA) and ELM to predict the water inrush. The above-mentioned studies improved the coal mine water inrush prediction model, but they still have some limitations: (1) Linear models such as Fisher model and Bayes model generally have low accuracy in discriminating multi-factor, nonlinear and discrete coal mine water inrush accidents (Zhang et al. 2021b). (2) Artificial neural networks (Zhang et al. 2020a), such as backpropagation neural networks (BPNN) and support vector machines (SVM), have problems of low convergence efficiency and easy to fall into local minima.

The ELM algorithm randomly generates the connection weight between the input layer and the hidden layer and the threshold of the hidden layer neurons, and no adjustment is required in the training process. The only optimal solution can be obtained by setting the number of hidden layer neurons. Compared with the previous traditional training methods, the ELM method has the advantages of fast learning and good generalization performance. However, the original ELM model had over-fitting problem, slow convergence speed and weight deviation caused by random parameter allocation, which affected the prediction accuracy of the model (Zhang et al. 2021a, c). In view of the shortcomings of deep neural network algorithm, it is the mainstream view to optimize and repair it. Among them, the simulated annealing particle swarm optimization (SAPSO) algorithm has the advantages of simple rules, parallel calculation, global optimization, easy implementation, high precision, fast convergence, etc., which has attracted the attention of the academic circle and demonstrated its advantages in solving practical problems.

Therefore, SAPSO algorithm was innovatively proposed in this paper to optimize the connection weight $\omega$ and threshold $B$ in ELM, so as to accelerate the convergence of iterative calculation and avoid local optimization and overfitting problems. Considering that coal mine water inrush is a complex process affected by synergistic effects of various factors, this paper divides these factors into 5 main indicators and 14 branch factors based on long-term accumulated data of mine water inrush cases (as shown in Fig. 1). Then, factor analysis (FA) method was used to add comprehensive factor indexes to enrich the data and reduce the dimension of influencing factors of water inrush. The discriminant factor obtained from FA was used as the input variable of SAPSOELM model to create a new intelligent prediction model of coal mine water inrush, and the performance of the same data set was compared with that of the traditional algorithm, as described below.

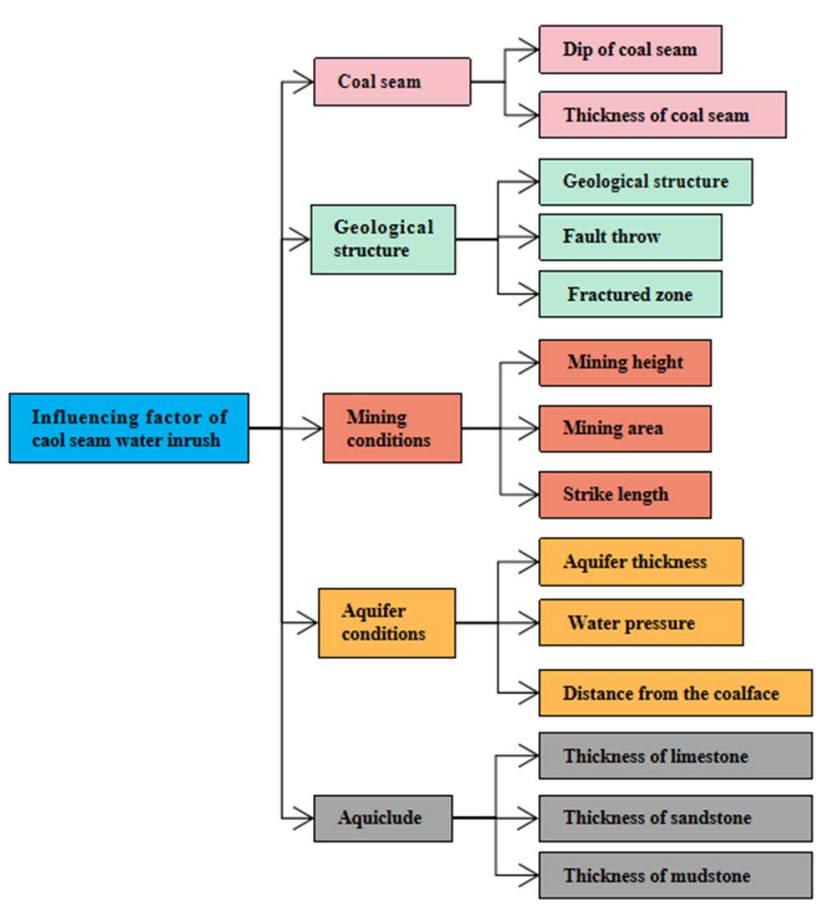

Fig. 1 The division of the influencing factors of coal mine water inrush (Zhang and Yang (2021)) 


\section{Algorithm theory}

\section{Extreme learning machine}

ELM algorithm is a new algorithm for single hidden layer feedforward neural network (see Fig. 2). The traditional feedforward neural network has defects such as slow training speed, easy to fall into local minimum point and sensitivity to initial selection (Zhang et al. 2020b, 2021a, c). However, since the ELM algorithm randomly generates the connection weight of the input layer and the hidden layer and the threshold of the hidden layer neuron, and no adjustment is required in the training process, only the number of hidden layer neuron is needed to obtain the unique optimal solution. Compared with the previous traditional training methods, the ELM method has the advantages of fast learning and good generalization performance. In terms of setting key parameters of ELM code, it is generally assumed that the input layer, hidden layer and output layer of a neural network respectively have $n, l, m$ neurons and the activation function of the hidden layer is $g(x)$ which is Sigmoid type; the mathematical model of ELM is noted as

$t_{i}=\sum_{i=1}^{L} \beta_{i} g_{i}\left(x_{i}\right)=\sum_{i=1}^{L} \beta_{i} g_{i}\left(\omega_{i} x_{j}+b_{i}\right)$

where $x_{i}=\left(x_{i 1}, x_{i 1}, \cdots x_{i n}\right)^{T} \in R_{n}$ is the input vector; $t_{i}=\left(t_{i 1}, t_{i 2}, \cdots t_{i n}\right)^{T} \in R_{n}$ is the output vector; $i=1,2, \cdots, N ;\left(\omega_{1}, \omega_{2}, \cdots, \omega_{n}\right)$ is the connection weight between $i$-th neuron in the input layer and neurons in the hidden layer; $\beta_{i}=\left(\beta_{1}, \beta_{2}, \cdots \beta_{m}\right)^{T}$ is the connection weight between $i$-th neuron in the hidden layer and neurons in the output layer, $j=1,2, \cdots, N ; b_{i}=\left(b_{1}, b_{2}, \cdots, b_{m}\right)^{T}$ is $i$-th bias node in the hidden layer.

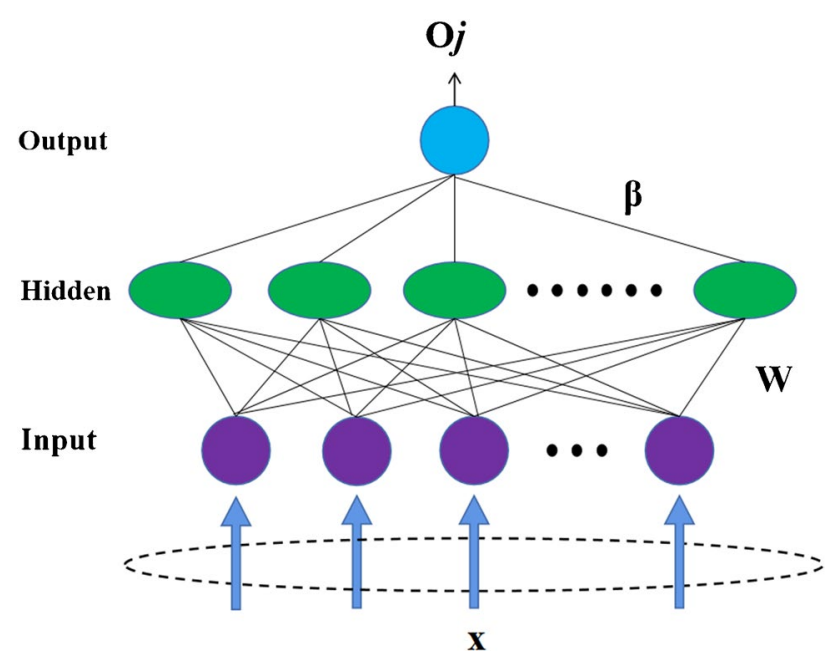

Fig. 2 The structure of ELM model
The output of the neural network is

$H \beta=T$

where in matrix form is noted as

$H=\left(\begin{array}{cccc}g\left(\omega_{1} x_{1}+b_{1}\right) & g\left(\omega_{2} x_{1}+b_{2}\right) & \cdots & g\left(\omega_{L} x_{1}+b_{L}\right) \\ g\left(\omega_{1} x_{2}+b_{1}\right) & g\left(\omega_{2} x_{2}+b_{2}\right) & \cdots & g\left(\omega_{L} x_{2}+b_{L}\right) \\ \vdots & \vdots & & \vdots \\ g\left(\omega_{1} x_{N}+b_{1}\right) & g\left(\omega_{2} x_{N}+b_{2}\right) & \cdots & g\left(\omega_{L} x_{N}+b_{L}\right)\end{array}\right) N x L$

$\beta_{\mathrm{i}}=\left(\beta_{1}^{T}, \beta_{2}^{T}, \cdots, \beta_{L_{L}}^{T}\right)^{T}$

$T=\left(t_{1}^{T}, t_{2}^{T}, \cdots, t_{m}^{T}\right)^{T}$

where $H$ is the output matrix of the hidden layer in the neural network.

\section{Simulated annealing particle swarm optimization algorithm (SAPSO)}

Particle swarm optimization (PSO) is a swarm-based intelligent optimization algorithm (Cai et al. 2021). With using real numbers to solve and fewer parameters to adjust, PSO is kind of a universal global search algorithm. However, PSO is subject to falling into local extreme points and slow convergence in the later stage of evolution; the idea of simulated annealing is hereby introduced. Simulated annealing (SA), using a thermodynamic system in simulation and optimization problems, has the following properties (Yuchi et al. 2021). In early stage, SA with high temperature has a strong global search capability. As the iteration progresses, the temperature of SA decreases, and a fine search is conducted following the rule of Metropolis sampling with a probabilistic jumping distribution, which can effectively avoid falling into a local minimum solution.

\section{Steps of optimized ELM with SAPSO}

The main process of the SAPSO algorithm is particle swarm optimization. After introducing the solid annealing principle and combining the adaptive inertia weight adjustment strategy and the group fitness variance, the global and local search capabilities of the PSO algorithm are balanced. For randomly generated input weights and hidden layer thresholds from ELM, more neurons of hidden layer are required to result in an over-fitting problem. The fitness variance of population is used as the basis for judging the precocity of particle swarms, combined with SAPSO's global search and the ability to jump out of local optimal solutions to dynamically optimize the input weights and hidden layer thresholds of ELM, so that ELM only needs less neurons in the hidden layer to achieve a rather good prediction, thereby, avoiding the algorithm falling into local extreme points and improving the speed 
and accuracy of convergence in later stage of evolution and the generalization of the network. To optimize the input layer weightand the hidden layer threshold of ELMwith SAPSO algorithm, more specific steps are described (in Fig. 3). More specific steps are as follows:

Step 1. Normalized transformation of the sample data; set the number of neurons and hidden nodes; select the activization function.

Step 2. Initialize model parameters, including the initial population size $M$, the initial temperature $T$ and cooling rate $\alpha$, the velocity and position of all particles in the target space, learning factors $c_{1}$ and $c_{2}$, inertia factor $\omega$. Set the termination conditions of iteration, such as the maximum number of iterations $K$ and the minimum error standard $E$. Minimum error is adopted as the iteration termination condition of this paper through error extreme value judgment; of course, there is manual participation in the judgment process of selection.

Step 3. Load the standardized training samples and then train according to Eqs. (2) and (3). Calculate the fitness function using the mean square error of the training sample error, according to Eq. (4).

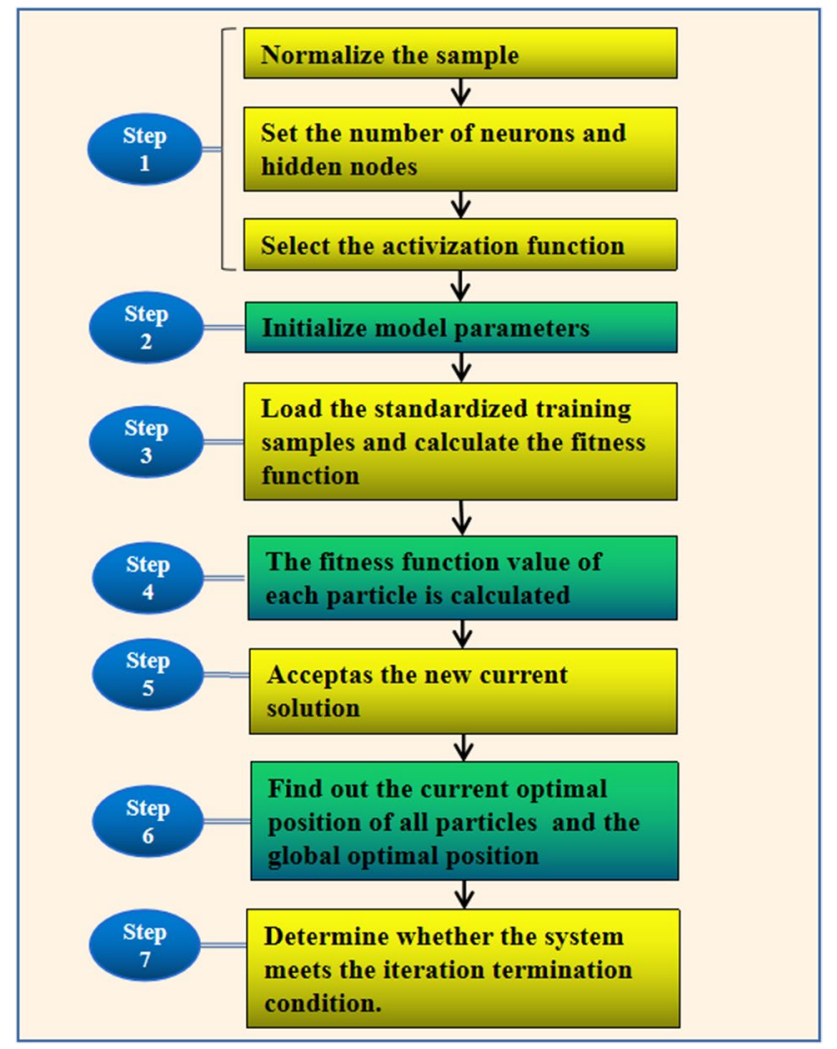

Fig. 3 Optimization flow chart of SAPSO-ELM
$E=\frac{1}{N} \sum_{i=1}^{N} \sqrt{\left(y_{i}-y_{i}\right)^{2}}$

Step 4. In each iteration, a new solution $x$ is generated, and the fitness function value of each particle is calculated. The increment is calculated in Eq. (5), where $f(x)$ is the evaluation function.

$\Delta E=f^{K+1}\left(x_{i}\right)-f^{k}\left(x_{i}\right)$

Step 5. If $\Delta E<0$, accept $x$ as the new current solution and update the system temperature according to Eq. (7); otherwise, the temperature remains unchanged and $T$ gradually decreases and tends to 0 after iteration.

$\exp \left(-\frac{\Delta E}{T}\right)>$ rand,$\Delta E<0$

$T^{K+1}=\alpha T^{K}$

where $\alpha$ is cooling rate.

Step 6. Update the velocity and position of particles according to Eqs. (8) to (10), and adjust the adaptive inertia weight $\omega$ and calculate the fitness function of each particle. Find out the current optimal position of all particles $p_{i d}$ and the global optimal position $p_{g d}$.

$V_{i d}^{\prime}=\omega V_{i d}+c_{1} r_{1}\left(p_{i d}-X_{i d}\right)+c_{2} r_{2}\left(p_{g d}-X_{g d}\right)$

$X_{i d}^{\prime}=X_{i d}+V_{i d}$

$\left\{\begin{array}{c}v_{i d}=v_{\max } \quad \text { if } v_{i d} \triangleright v_{\max } \\ v_{i d}=v_{\min } i \quad f v_{i d} \triangleleft v_{\min }\end{array}\right.$

$\omega_{t}=\omega_{\max }-t \frac{\omega_{\max }-\omega_{\min }}{T}$

where $i=1,2,3, \cdots, M ; d=1,2,3, \cdots, D ; \omega$ is the inertia weighting factor for adjusting the flying velocity of particles; $x_{i d}$ and $v_{i d}$ are the position and velocity of particle $i$ in the $d$-th dimension.

Step 7. Determine whether the system meets the iteration termination condition. If it reaches, the iteration stops and $P_{g d}$ at this time is the optimal $(\omega, b)$, which is substituted into the ELM network for training. The output weight $\beta$ and the actual output matrix $T$ are calculated according to Eqs. (2) and (3); otherwise, continue the iteration from Step 3.

Since particle swarm optimization (PSO) has the parameter adjustment mechanism of communication among particles, the training of given samples is as close 


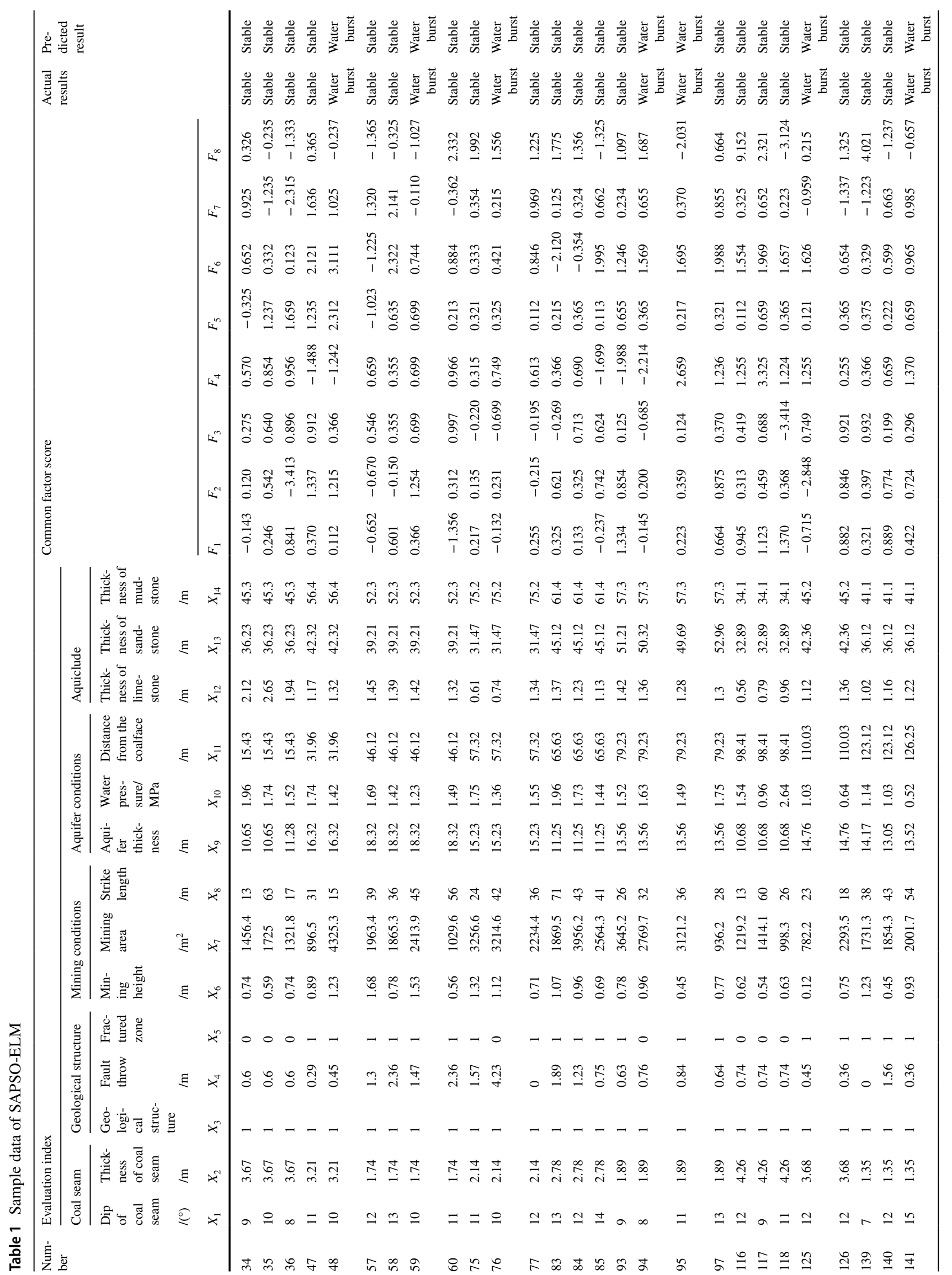




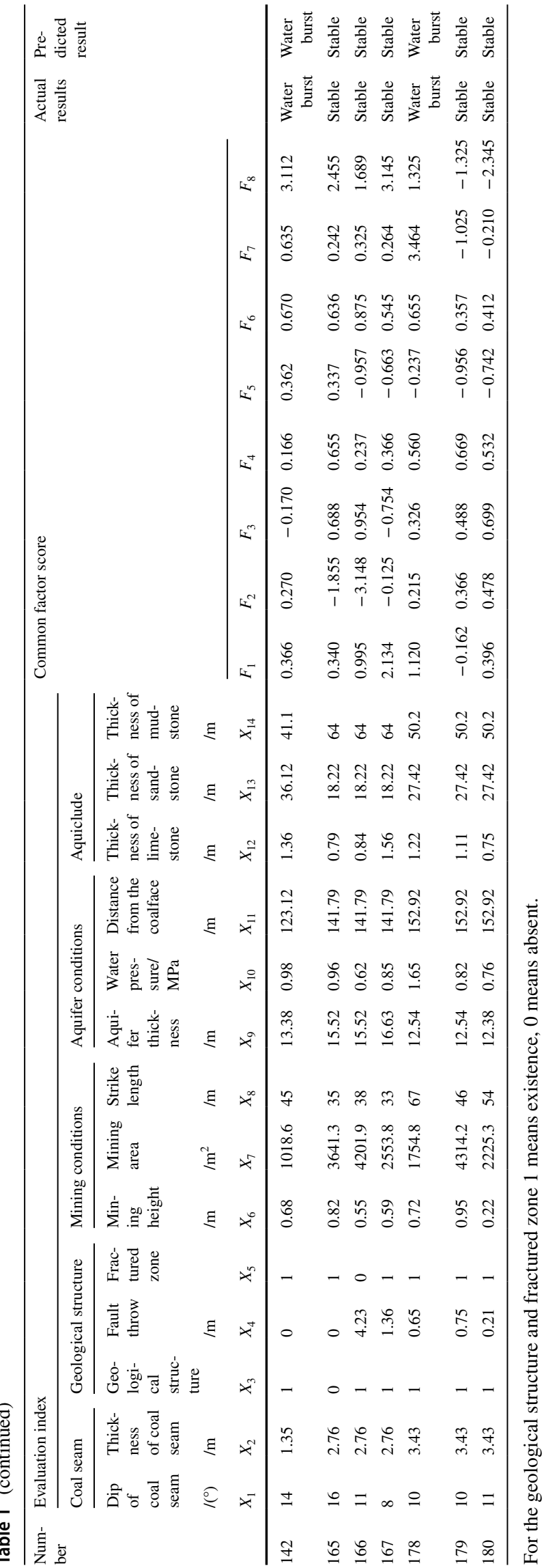

as possible. The quality of the model can only be judged by the error of the prediction validation sample.

\section{Data sources and preprocessing}

\section{Data sources}

The process of coal mine water inrush is a complex dynamic system. This paper uses the water inrush data collected from the working face floor and measured normal mining data of a mining area in China where water inrush happened. The original data is collected at different times and locations and has not been sorted and grouped. A total of 180 groups of measured water inrush data in a coal mine were used as the total data set (partially shown in Table 1) to establish a coal mine water inrush prediction model. Among which, $80 \%$ (144 groups) were used as the training group, and the remaining 36 groups were used as test samples to test the learning effect of the model.

\section{Pretreatment of influencing factors}

Various factors control the process of water inrush in mining. The original data (influencing factors) need to be preprocessed to determine the correlation between coal mine indicators and water inrush and test whether dimension reduction can be carried out. All selected indicators were analyzed by Pearson in SPSS 17.0 (a data analysis software) to reduce information overlap among indicators. The correlation coefficients of statistic sig. function and $t$ test were calculated by correlation matrix. The effects of these factors are described and explained as shown in Fig. 4 (Zhang and Yang 2021).

The analysis results show that the absolute correlation coefficients between the two indicators in 14 indicators $\left(\mathrm{X}_{1}-\mathrm{X}_{14}\right.$ in Table 1) are all greater than 0.7; Sig. function value is less than 0.01 , and the correlation coefficient is not 0 , indicating that these 14 indicators have overlapping influence on water inrush from coal floor. The input data of the network is the result of water inrush, which are classified as stable and water burst. The SAPSO-ELM algorithm is used to establish a coal mine water inrush prediction model. Based on this algorithm, how the selected indicators affect the water inrush was studied through training samples data.

\section{Influencing factor analysis}

Apparent correlation between 14 indicators was confirmed by Pearson correlation coefficient analysis. If these 14 indicators were set as input vectors of SAPSO-ELM prediction model directly, data redundancy may reduce the 


\begin{tabular}{|c|c|}
\hline No. & Description of influencing factors \\
\hline 1 & $\begin{array}{l}\text { Confined aquifer is the prerequisite for water inrush due to the supply of mine water and source of confined pressure on subsurface } \\
\text { fluid; }\end{array}$ \\
\hline 2 & $\begin{array}{l}\text { Geological structures, mainly considering fissures and faults are main conductive conduits for subsurface fluid flow under certain } \\
\text { stress and strain; }\end{array}$ \\
\hline 3 & $\begin{array}{l}\text { Mining geomechanics directly trigger the growth of fractures and cracks in the direction of minimum principal stress, which usually } \\
\text { develops secondary conductive conduits under the influence of other factors mentioned in our study, enhancing the probability of } \\
\text { water inrush during mining; }\end{array}$ \\
\hline 4 & $\begin{array}{l}\text { Based on the 'Down Three Zone' theory, mining activities directly form the destroyed conductive zone. The depth of destroyed } \\
\text { conductive zone is controlled by the mining height, dip angle of coal seam and inclined length of workface. A safe thickness of the } \\
\text { protective layer during mining can be decreased with a lower depth of the destroyed conductive zone. This depth is also determined } \\
\text { by considering the mining area, mining height and dip length to different extents. When dealing with thick coal seam, seam mining is } \\
\text { usually chosen to be accomplished layers by layers. }\end{array}$ \\
\hline 5 & $\begin{array}{l}\text { The biggest damage on each mining layer all happens on the first mining activities, and the influence of mining will gradually } \\
\text { decrease in the process of mining. However, the depth of destroyed conductive zone increases permanently. Mining has a low } \\
\text { influence on damage of the coal seam with a low dip angle and inclined length of workface. This influence expands with a higher } \\
\text { angle and apparent length. }\end{array}$ \\
\hline 6 & $\begin{array}{l}\text { Mining height controls the water inrush like other factors, with a lower influence compared to the length of workface. A } 100 \text {-meter } \\
\text { mining height leads to } 0.8 \mathrm{~m} \text { depth of the damaged statistically. }\end{array}$ \\
\hline 7 & Aquifer conditions are the only factors which may prevent the water inrush; \\
\hline 8 & $\begin{array}{l}\text { Changes of stress state is the vital reason for induced seismicity and changes the transmissivity of geological discontinuities, usually } \\
\text { having a positive influence on the start of water inrush. }\end{array}$ \\
\hline
\end{tabular}

Fig. 4 Description of influencing factors

reliability of prediction model. Therefore, it is necessary to use factor analysis (FA) to improve the independence between discriminant indicators. To ensure the reliability of attribute selection, it is essential to check whether it is suitable for factor analysis before performing factor analysis. Kaiser-Meyer-Olkin (KMO) and Bartlett's test on these 14 inner-correlated indicators were finished in SPSS, and results are shown in Table 2. The value of KMO is 0.843 indicating 14 indicators are correlated; the Sig. value of Bartlett's test is $0.000<0.010$. Both two tests suggested these 14 indicators are suitable for FA, and the purpose of dimensionality reduction can be achieved.

Table 2 KMO and Bartlett test

\begin{tabular}{lll}
\hline Factor & & Value \\
\hline KMO & & 0.843 \\
Bartlett & Chi-square & 112.75 \\
& $\mathrm{~d}_{f}$ & 18 \\
& Sig & 0 \\
\hline
\end{tabular}

Table 3 Total variance explaining table of common factor

\begin{tabular}{llll}
\hline No & Sum & $\begin{array}{l}\text { Contribution } \\
\text { rate/\% }\end{array}$ & $\begin{array}{l}\text { Accumulated } \\
\text { contribution } \\
\text { rate/\% }\end{array}$ \\
\hline 1 & 1.736 & 12.4 & 12.4 \\
2 & 1.8648 & 13.32 & 25.72 \\
3 & 1.925 & 13.75 & 39.47 \\
4 & 1.7934 & 12.81 & 52.28 \\
5 & 1.89 & 13.5 & 65.78 \\
6 & 1.4546 & 10.39 & 76.17 \\
7 & 1.3552 & 9.68 & 85.85 \\
8 & 0.6496 & 4.64 & 90.49 \\
9 & 0.5446 & 3.89 & 94.38 \\
10 & 0.2632 & 1.88 & 96.26 \\
11 & 0.1344 & 0.96 & 97.22 \\
12 & 0.0742 & 0.53 & 97.75 \\
13 & 0.2058 & 1.47 & 99.22 \\
14 & 0.1092 & 0.78 & 100 \\
\hline
\end{tabular}



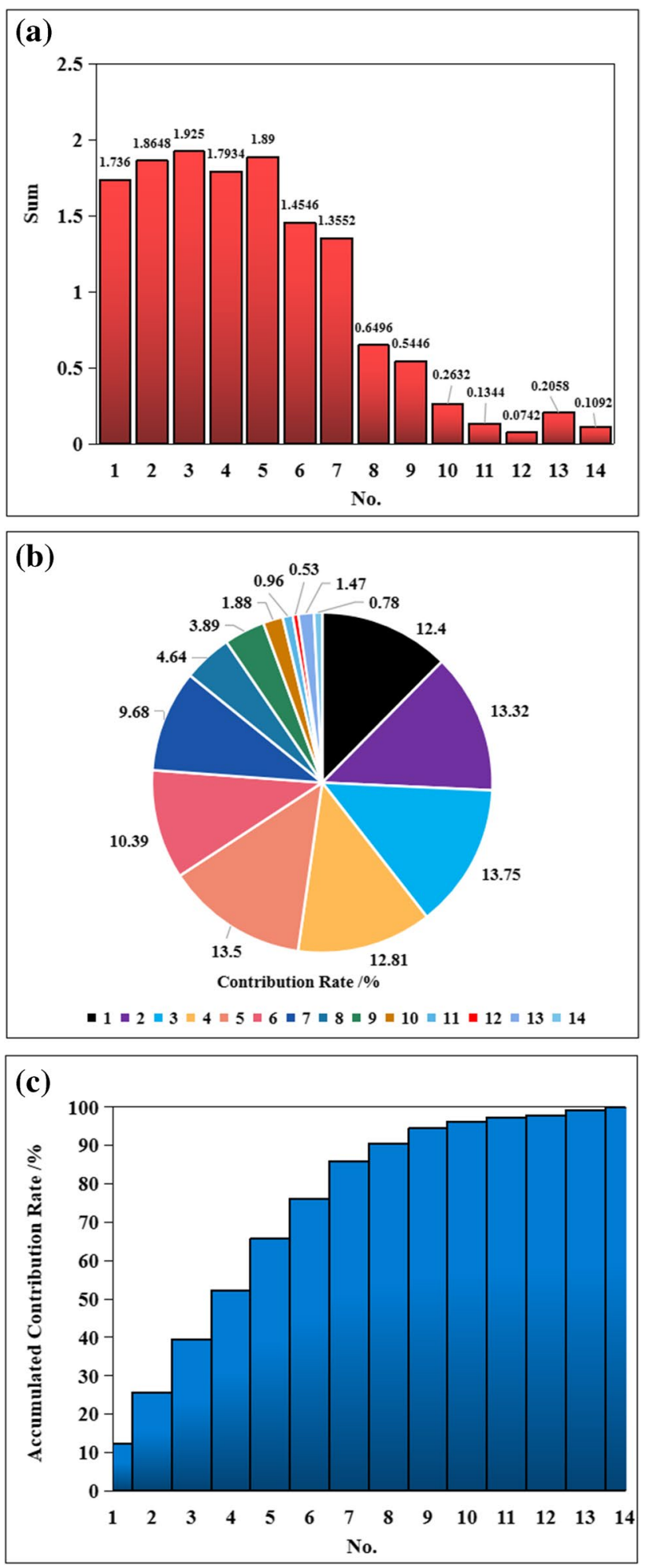

Fig. 5 Total variance explaining of common factor

\section{Results and discussion}

\section{SAPSO-ELM water inrush prediction model based on FA}

A total of 144 sets of measured data of coal mine water inrush are used as training samples for the prediction model, and another 36 sets of sample data are used as test samples for the prediction model. In the coal mine water inrush forecasting, in order to reduce the information redundancy between indicators and improve the mutual independence, 14 correlated discriminant indicators were analyzed by FA, and the total variance of common factors was obtained, as shown in Table 3. It can be seen in Table 3 and Fig. 5 that the accumulation of the first 8 common factors accounts for $90.49 \%$ of total variance; therefore, these 8 components which can explain the variance of the original variables are determined to be common factors in the model.

The original factors are so comprehensive that cannot reflect the influence on water inrush independently. A loading factor matrix is rotated to maximize the variance, so that the number of high-loading variables on each factor is minimized, thereby reducing the comprehensiveness of factors and obtaining the rotated matrix (shown in Table 4). The magnitude of the absolute value of the numerical value in Table 4 indicates the degree of correlation between the public factor variable and the original variable. The public factor $F_{1}$ reflects $X_{1}$ and $X_{2} ; F_{2}$ reflects $X_{4}$ and $X_{5} ; F_{3}$ reflects $X_{6}$ and $X_{7} ; F_{4}$ reflects $X_{10}$ and $X_{11} ; F_{5}$ reflects $X_{3}$ and $X_{8} ; F_{6}$ reflects $X_{9} ; F_{7}$ reflects $X_{12} ; F_{8}$ reflects $X_{13}$ and $X_{14}$. All values of these 8 factors in matrix were obtained from the regression method and shown in Table 1.

These 8 main discriminant factors: $F_{1}, F_{2}, F_{3}, F_{4}, F_{5}, F_{6}$, $F_{7}, F_{8}$ are the input vectors of the coal mine water inrush prediction model which is a SAPSO-ELM model established with FA. A training program of Matlab was used, and its basic parameters were initialized according to the experimental and trial calculations of two original models SAPSO and PSO, which are population size 20, maximum number of iterations 200 , learning factors $c_{1}=2.6, c_{2}=1.5$, inertia weight $\omega_{\max }=0.9, \omega_{\min }=0.5$, starting and ending temperature $T_{0}=200, T=10$, cooling rate $\alpha=0.9$, and the allowable error is 0.01 . A total of 144 sets of data from Table 1 were trained, and a nonlinear model of discriminant factors and water inrush was established. 
Table 4 Rotated component matrix

\begin{tabular}{lllllllll}
\hline Indicators & $F_{1}$ & $F_{2}$ & $F_{3}$ & $F_{4}$ & $F_{5}$ & $F_{6}$ & $F_{7}$ & $F_{8}$ \\
\hline$X_{1}$ & 0.912 & 0.312 & 0.563 & 0.163 & 0.046 & 0.114 & 0.222 & 0.133 \\
$X_{2}$ & 0.845 & 0.112 & 0.123 & 0.221 & 0.414 & 0.232 & 0.302 & 0.104 \\
$X_{4}$ & 0.213 & 0.756 & 0.321 & 0.236 & 0.219 & 0.135 & 0.136 & 0.903 \\
$X_{5}$ & 0.174 & 0.866 & 0.155 & 0.095 & 0.169 & 0.321 & 0.255 & 0.855 \\
$X_{6}$ & 0.103 & 0.184 & 0.923 & 0.076 & 0.098 & 0.364 & 0.165 & 0.274 \\
$X_{7}$ & 0.086 & 0.213 & 0.795 & 0.109 & 0.188 & 0.234 & 0.425 & 0.309 \\
$X_{10}$ & 0.312 & 0.163 & 0.169 & 0.842 & 0.179 & 0.177 & 0.129 & 0.152 \\
$X_{11}$ & 0.112 & 0.218 & 0.213 & 0.878 & 0.133 & 0.129 & 0.231 & 0.401 \\
$X_{3}$ & 0.153 & 0.141 & 0.265 & 0.142 & 0.779 & 0.111 & 0.144 & 0.223 \\
$X_{8}$ & 0.214 & 0.321 & 0.403 & 0.213 & 0.886 & 0.067 & 0.162 & 0.115 \\
$X_{9}$ & 0.175 & 0.423 & 0.106 & 0.312 & 0.177 & 0.812 & 0.149 & 0.166 \\
$X_{12}$ & 0.123 & 0.065 & 0.151 & 0.156 & 0.145 & 0.211 & 0.937 & 0.162 \\
$X_{13}$ & 0.096 & 0.079 & 0.174 & 0.077 & 0.081 & 0.119 & 0.209 & 0.839 \\
$X_{14}$ & 0.109 & 0.069 & 0.173 & 0.244 & 0.092 & 0.238 & 0.246 & 0.769 \\
\hline
\end{tabular}

The fitness curve of PSO-ELM and SAPSO-ELM was seen in Fig. 6. In PSO-ELM, after 160 times of iteration, system error became stable around 0.23 while in SAPSO-ELM was after 120 times and with a lower system error 0.10. Results showed that SAPSO-ELM has a faster optimization speed and higher convergence accuracy. The learning efficiency of ELM model is significantly improved by SAPSO.

\section{Comparative analysis of SAPSO-ELM model}

In order to verify the reliability of the SAPSO-ELM model in terms of coal mine water inrush, the back-substitution estimation method was used to conduct multiple test during

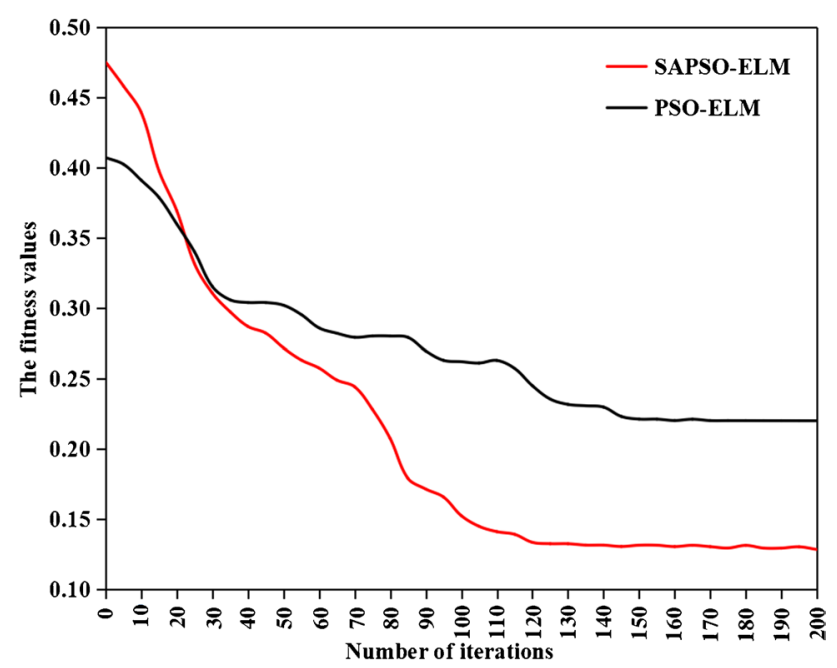

Fig. 6 Curve of the fitness values the training of the model. The judgment of the model was consistent with the actual results of coal mine water inrush, and the misjudgment rate was $5.6 \%$. To further verify the superiority of the SAPSO-ELM model, the prediction results of the commonly used SVM model and the BPNN are compared and the comparison results are shown in Figs. 7 and 8. Also, the coal mine water inrush prediction models based on ELM, PSO-ELM and SAPSO-ELM were compared from the perspective of running time and accuracy. The results are shown in Figs. 9 and 10.

From Figs. 7 and 8, the prediction result of SAPSOELM model was closer to the occurrence of coal mine water inrush in an actual mine. However, the remaining 2 prediction results from the other models are not as good as the SAPSO-ELM. The accuracy of the SVM model for the test sample prediction is $88.3 \%$, and BPNN model is only $72.2 \%$. The misjudgment case of SAPSO-ELM is 5.6\% which is much better than SVM and BPNN. It can be obviously concluded that the SAPSO-ELM prediction model established by FA is more accurate and suitable for these intelligent prediction models of multi-factor complex water inrush of coal mine.

Similarly, the same conclusion can be drawn from the comparative analysis of Figs. 9 and 10. After the original parameters were reduced by FA method, the accuracy of ELM, PSO-ELM and SAPSO-ELM models was improved, and the running time was $0.112356 \mathrm{~s}, 0.243654 \mathrm{~s}$ and $0.203254 \mathrm{~s}$, respectively, which were much faster than the original parameters. Therefore, the SAPSO-ELM model optimized by FA method is efficient and accurate in coal mine water inrush prediction. It is proved that the model can be further applied to more coal mine water inrush prediction, and a more universal water inrush prediction system can be trained in a larger case data system. 
Fig. 7 Comparison of prediction results of different models
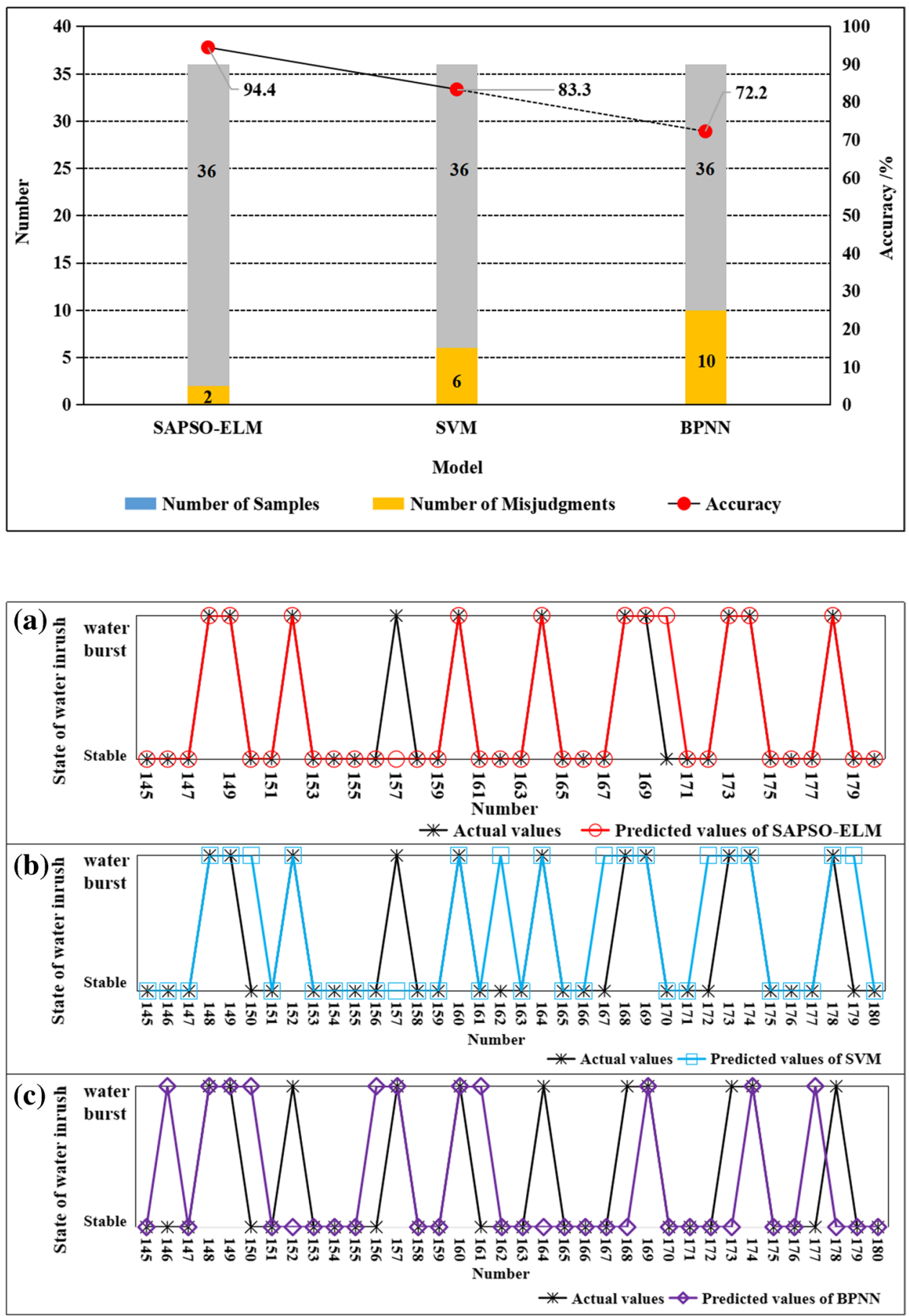

Fig. 8 Comparison of measured data and predicted data in test data of different model

\section{Conclusion}

This paper proposes the SAPSO to optimize the connection weight $\omega$ and threshold $b$ in ELM. Subsequently, the SAPSO-ELM-based coal mine water inrush prediction model is established, where the factor analysis (FA) is conducted to enrich the data. To reduce the dimensionality of the influencing factors of water inrush, the discriminant factors are obtained from the FA, which are used as the input variables of SAPSO-ELM model. Therefore, the following conclusions can be drawn based on the above research results:

(1) FA method is feasible for correlation analysis of multifactor analysis. The analysis shows that the $\mathrm{X} 1-\mathrm{X} 14$ 
Fig. 9 Comparison of the running time of different models

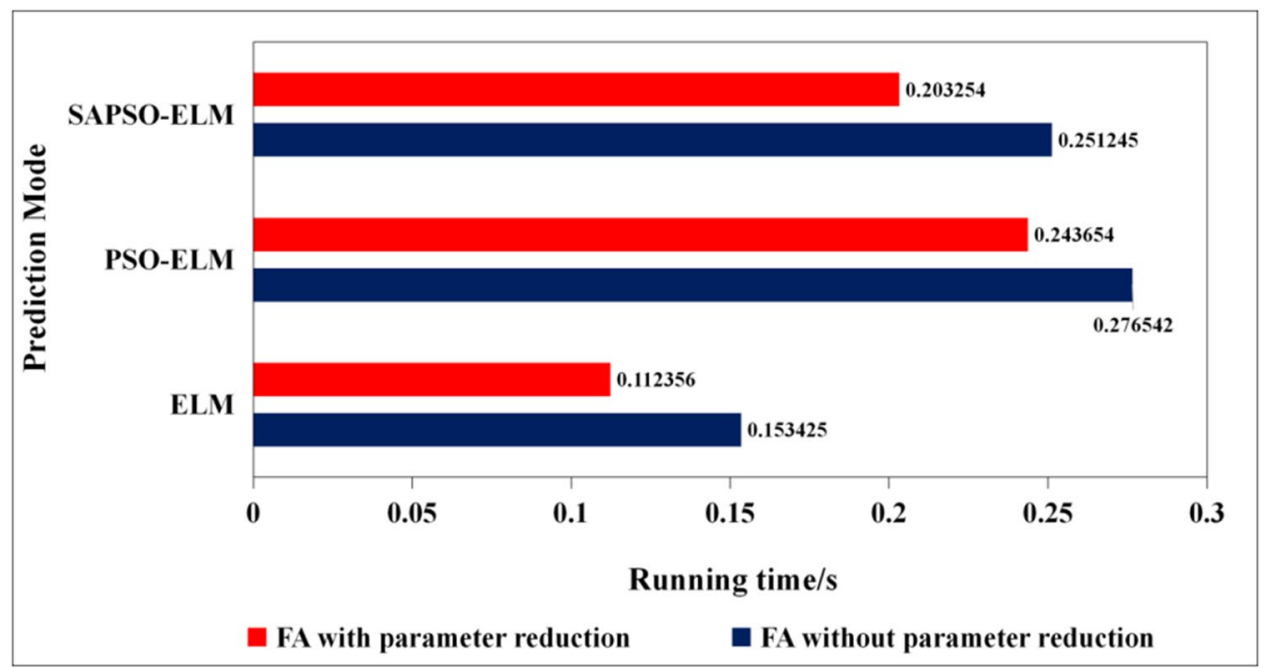

Fig. 10 Accuracy comparison of the different models

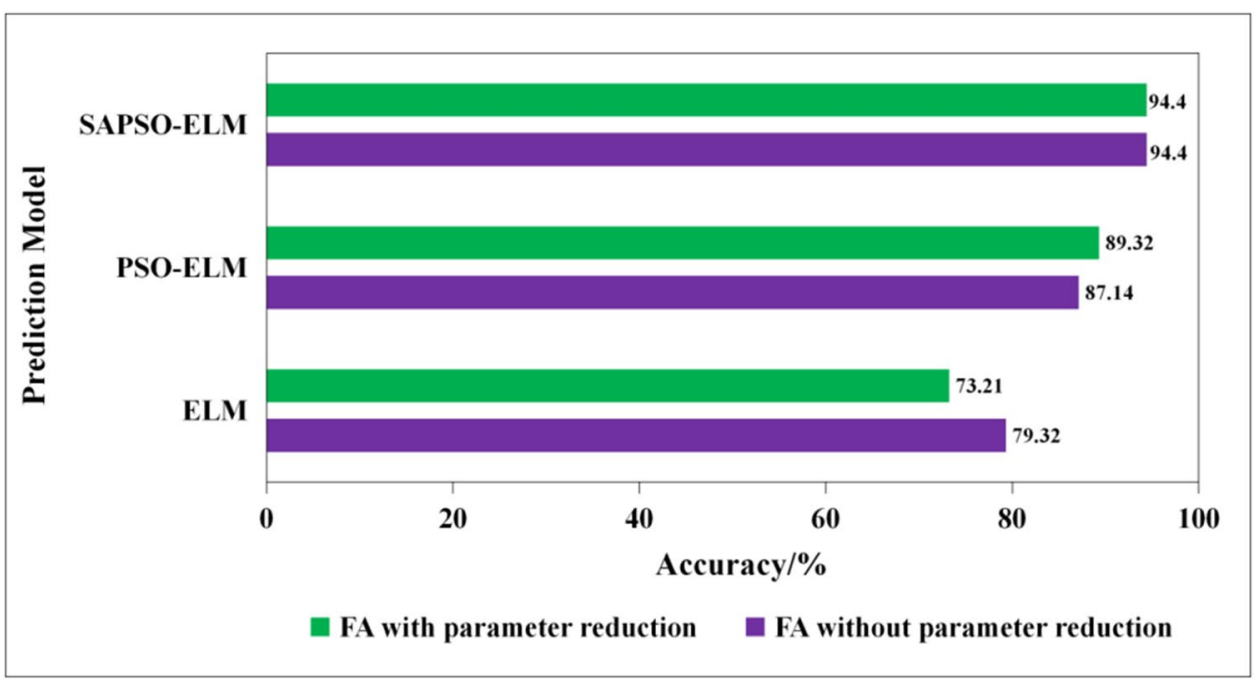

index has a strong correlation with water inrush in coal mine.

(2) The comprehensive scoring factors F1, F2, F3, F4, F5, F6, F7 and F8 obtained by FA method as the input of SAPSO-ELM model can accelerate the convergence speed of SAPSO-ELM model.

(3) Compared with SVM, BPNN, PSO-ELM and ELM, the SAPSO-ELM model established by FA has higher accuracy and faster convergence. SAPSO significantly improved the learning efficiency of ELM model.

Considering that the data set used for learning is mainly from a coal mine and the data volume is relatively small, the superiority of the proposed model is not fully reflected, but it still shows considerable application prospects. More data, more complex geological conditions and more case data are needed to improve the accuracy and efficiency of the prediction model for further research.
Acknowledgements This work would like to thank Dr. Yuanlun Xie from the University of Electronic Science and Technology of China for his help with the algorithm, Dr. Lining Yang for his language polish and Dr. Raoping Liao and Dr. Tao Chou for his help and support in the revision of the paper.

\section{Declarations}

Conflict of interest The authors declare no competing interests.

Open Access This article is licensed under a Creative Commons Attribution 4.0 International License, which permits use, sharing, adaptation, distribution and reproduction in any medium or format, as long as you give appropriate credit to the original author(s) and the source, provide a link to the Creative Commons licence, and indicate if changes were made. The images or other third party material in this article are included in the article's Creative Commons licence, unless indicated otherwise in a credit line to the material. If material is not included in the article's Creative Commons licence and your intended use is not permitted by statutory regulation or exceeds the permitted use, you will 
need to obtain permission directly from the copyright holder. To view a copy of this licence, visit http://creativecommons.org/licenses/by/4.0/.

\section{References}

Bai HB, Miao XX (2009) Research progress and major problems of water preserved coal mining. J Min Saf Eng 26(3):253-262

Cai B, Zhu XP, Qin YX (2021) Parameters optimization of hybrid strategy recommendation based on particle swarm algorithm. Expert Syst Appl. https://doi.org/10.1016/j.eswa.2020.114388

Du CL, Zhang XY, Li FL (2014) Application of improved CART algorithm in prediction of water inrush from coal seam floor. Ind Mine Autom 40(12):52-56 (in Chinese)

He MM, Zhang ZQ, Zheng J, Chen FF, Li N (2020a) A new perspective on the constant $\mathrm{m}$ (i) of the Hoek-Brown failure criterion and a new model for determining the residual strength of rock. Rock Mech Rock Eng 53(9):3953-3967

He MM, Li N, Zhu J, Chen YS (2020b) Advanced prediction for field strength parameters of rock using drilling operational data from impregnated diamond bit. J Petrol Sci Eng 187:106847

Jin DW, Zheng G, Liu ZB, Liu YF, Pang XQ (2011) Real-time monitoring and early warning techniques of water inrush through coal floor. Procedia Earth Planet Sci 3:37-46 (in Chinese)

Li FJ (2010) The prediction and forecast of coal floor water-inrush based on gis: a case study on the 1-1 mining district in the 5\# coal mine in Pingdingshan area. Environ Sci Inf Appl Technol 2:663-666 (in Chinese)

Liu BZ, Jin DW, Liu QS (2009) Prediction of water inrush through coal floor based on binary logistic regression mode and CART. Coal Geol Explor 7(1):56-61 (in Chinese)

Liu ZB, Jin DW, Liu QS (2011) Prediction of water inrush through coal floors based on data mining classification technique. Procedia Earth Planet Sci 3:166-174 (in Chinese)

Liu SL, Dai S, Li WP, Han B, He B, Luo JP (2020) A new monitoring method for overlying strata failure height in Neogene laterite caused by underground coal mining. Eng Failure Anal 117:104796

Miao XX, Wang CS, Bai HB (2010) Hydrogeologic characteristics of mine water hazards in Shendong mining area. J Min Saf Eng 27(3):285-291+298

Qiu LM, Song DZ, Li ZH, Liu BB, Liu J (2019) Research on AE and EMR response law of the driving face passing through the fault. Saf Sci 17:184-193

Qiu LM, Liu ZT, Wang EY, He XQ, Feng JJ, Li BL (2020) Earlywarning of rock burst in coal mine by low-frequency electromagnetic radiation. Eng Geol. https://doi.org/10.1016/j.enggeo.2020. 105755

Rui G, Hao Y, Feng J, Mei XC, Wang XL (2018) Influential factors and control of water inrush in a coal seam as the main aquifer. Int J Min Sci Technol 28(2):187-193

Wang SS, Zhang WJ, Wei JC, Song BL (2012) Water-inrush prediction of coalbed floor based on the limit equilibrium theory of rock mass. Natl Conf Inf Technol Comput Sci 12(2):61-64
Wu Q, Zhou W (2008) Prediction of groundwater inrush into coal mines from aquifers underlying the coal seams in China: vulnerability index method and its construction. Environ Geol 55(4):245-254

Yan ZG, Bai HB, Zhang HR (2008) A novel SVM model for the analysis and prediction of water inrush from coal mine. China Saf Sci J 18(7):166-170 (in Chinese)

Yu BY, Chen ZQ, Yu LL (2016) Water-resisting ability of cemented broken rocks. Int J Min Sci Technol 26(3):449-454

Yuchi Q, Wang NM, He ZW, Chen HX (2021) Hybrid heuristic for the location-inventory-routing problem in closed-loop supply chain. Int Trans Oper Res 28(3):1265-1295

Zhang YG, Yang LN (2021) A novel dynamic predictive method of water inrush from coal floor based on gated recurrent unit model. Nat Hazards 105(2):2027-2043. https://doi.org/10.1007/ s11069-020-04388-9

Zhang BY, Bai HB, Zhang K (2016) Seepage characteristics of collapse column fillings. Int J Min Sci Technol 26(2):333-338

Zhang YG, Tang J, Liao RP, Zhang MF, Zhang Y, Wang XM, Su ZY (2020a) Application of an enhanced BP neural network model with water cycle algorithm on landslide prediction. Stoch Environ Res Ris A. https://doi.org/10.1007/s00477-020-01920-y

Zhang LG, Chen XQ, Zhang YG, Wu FW, Chen F, Wang WT, Guo F (2020b) Application of GWO-ELM model to prediction of Caojiatuo landslide displacement in the Three Gorge Reservoir Area. Water. https://www.mdpi.com/2073-4441/12/7/1860

Zhang HL, Tu M, Cheng H, Tang YZ (2020c) Breaking mechanism and control technology of sandstone straight roof in thin bedrock stope. Int J Min Sci Technol 30(2):259-263

Zhang YG, Qiu JB, Zhang Yan, Wei YY (2021a) The adoption of ELM to the prediction of soil liquefaction based on CPT. Nat Hazards. https://doi.org/10.1007/s11069-021-04594-Z

Zhang YG, Tang J, He ZY, Tan JK, Li C (2021b) A novel displacement prediction method using gated recurrent unit model with time series analysis in the Erdaohe landslide. Nat Hazards 105(1):783-813. https://doi.org/10.1007/s11069-020-04337-6

Zhang YG, Chen X, Liao R, Wan L, He Z, Zhao Z, Zhang Y, Su Z (2021c) Research on displacement prediction of step-type landslide under the influence of various environmental factors based on intelligent WCA-ELM in the Three Gorges Reservoir Area. Nat Hazard. https://doi.org/10.1007/s11069-021-04655-3

Zhang YG, Tang J, Cheng Y, Huang L, Guo F, Yin X, Li N (2022a). Prediction of landslide displacement with dynamic features using intelligent approaches. International Journal of Mining Science and Technology. https://doi.org/10.1016/j.ijmst.2022.02.004

Zhang Y, Zhang YG, Zhai C, Xie YL, Qiu J (2022b) The establishment of the prediction model of soil liquefaction based on capacity energy concept and rigid regression. Bulletin of Engineering Geology and the Environment. https://doi.org/10.1007/ s10064-022-02620-3

Zhao ZB, Li P, Xu XZ (2013) Forecasting model of coal mine water inrush based on extreme learning machine. Appl Math Inf Sci 3:1243-1250 ((in Chinese)) 